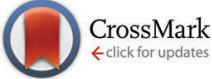

Cite this: Phys. Chem. Chem. Phys., 2016, 18, 21226

Received 13th January 2016, Accepted 24th May 2016

DOI: $10.1039 / \mathrm{c} 6 \mathrm{cp} 00235 \mathrm{~h}$

www.rsc.org/pccp

\section{Predictive thermodynamics for ionic solids and liquids $\dagger$}

\author{
Leslie Glasser*a and H. Donald Brooke Jenkins*b
}

The application of thermodynamics is simple, even if the theory may appear intimidating. We describe tools, developed over recent years, which make it easy to estimate often elusive thermodynamic parameter values, generally (but not exclusively) for ionic materials, both solid and liquid, as well as for their solid hydrates and solvates. The tools are termed volume-based thermodynamics (VBT) and thermodynamic difference rules (TDR), supplemented by the simple salt approximation (SSA) and single-ion values for volume, $V_{\mathrm{m}}$, heat capacity, $C_{\mathrm{p}}^{\circ}$, entropy, $S_{298}^{\circ}$, formation enthalpy, $\Delta_{\mathrm{f}} H^{\circ}$, and Gibbs formation energy, $\Delta_{\mathrm{f}} G^{\circ}$. These tools can be applied to provide values of thermodynamic and thermomechanical properties such as standard enthalpy of formation, $\Delta_{\mathrm{f}} H^{\circ}$, standard entropy, $S_{298}^{\circ}$, heat capacity, $C_{p}$, Gibbs function of formation, $\Delta_{f} G^{\circ}$, lattice potential energy, $U_{\mathrm{POT}}$, isothermal expansion coefficient, $\alpha$, and isothermal compressibility, $\beta$, and used to suggest the thermodynamic feasibility of reactions among condensed ionic phases. Because many of these methods yield results largely independent of crystal structure, they have been successfully extended to the important and developing class of ionic liquids as well as to new and hypothesised materials. Finally, these predictive methods are illustrated by application to $\mathrm{K}_{2} \mathrm{SnCl}_{6}$, for which known experimental results are available for comparison. A selection of applications of VBT and TDR is presented which have enabled input, usually in the form of thermodynamics, to be brought to bear on a range of topical problems. Perhaps the most significant advantage of VBT and TDR methods is their inherent simplicity in that they do not require a high level of computational expertise nor expensive highperformance computation tools - a spreadsheet will usually suffice - yet the techniques are extremely powerful and accessible to non-experts. The connection between formula unit volume, $V_{m}$, and standard thermodynamic parameters represents a major advance exploited by these techniques.

\section{Introduction}

Consider what obliges one to attempt to estimate the properties of a known inorganic material or predict the properties of an as-yet unprepared material. Examine the complexities! There are about 100 chemical elements, which combine to form about 100 million already-known compounds, of which some $10 \%$ could be classified as inorganic/mineral. ${ }^{1}$ There remains an almost limitless range of possible combinations as yet unexplored. By contrast, the most comprehensive current crystallographic databases report data on only about one million of these organic compounds and on only about one-quarter of a million inorganic

\footnotetext{
${ }^{a}$ Nanochemistry Research Institute, Department of Chemistry, Curtin University, Perth 6845, Western Australia, Australia. E-mail: l.glasser@curtin.edu.au; Fax: +61 8 9266-4699; Tel: +61 8 9848-3334

${ }^{b}$ Department of Chemistry, University of Warwick, Coventry, West Midlands CV4 7AL, UK. E-mail: h.d.b.jenkins@warwick.ac.uk; Fax: +44 (0)2476-466-747, +44 (0)2476-524-112; Tel: +44 (o)2476-466-747, +44 (0)2476-523-265

$\dagger$ Electronic supplementary information (ESI) available: Lists of predictive thermodynamic group estimation methods, and of thermodynamic databases. See DOI: 10.1039/c6сp00235h
}

compounds. ${ }^{2}$ Ionic liquids are combinations of such a broad range of cations and anions so that the in-principle possible number of such liquids is of the order of $10^{18}$ (although the realistically possible number is orders of magnitude smaller) already, some 1000 have been reported in the literature. ${ }^{3}$ On the other hand, thermodynamic data is available for only some 30000 compounds, of which about $60 \%$ (20 000) are inorganic (see ESI $\dagger$ for a list of thermodynamic data compendia). Thus, the chance of finding the property data one seeks is miniscule; add to this, the need to obtain data on as-yet unprepared material, such as might be required for a proposed synthesis. As a consequence, a number of simple empirical rules have been developed for a variety of thermodynamic properties (see Table 1).

The most basic data that needs to be obtained for this essentially unlimited set of materials is thermodynamic because such data informs us of the stability of the materials, our ability to synthesise them, and to maintain their integrity. In the absence of published data, the question then arises as to how one should proceed in order to obtain that data.

The most fundamental approach would be through quantum mechanical (QM) calculation, ${ }^{10}$ where one considers in detail 
how the fundamental particles of which a material consists, such as atoms and electrons, interact with one another through electrostatic forces, charge transfer, van der Waals (dispersion) interactions, electron correlation, and so forth. While such an approach has yielded important results, it is complex, uses expensive computation facilities, and requires considerable expertise in both application and interpretation. At a somewhat simpler level, density functional theory (DFT) ${ }^{11}$ has reduced the complexity of QM methods and, hence, their cost by relating the energetics to the more readily computable electron density of the material and using functions of the electron density function (that is, functionals) to derive experimentally observable results. DFT has found increasing favour in recent years in providing useful results but difficulties remain in dealing with dispersion and electron correlation. Thus, in stark contrast to the VBT approach, these QM approaches require considerable expertise to execute and interpret reliably.

A rational response has been to collect data on related materials and use that data to extrapolate (or interpolate) in order to estimate the properties of the material under investigation. We illustrate this approach in some general terms first, and then focus on an approach which we have termed volume-based thermodynamics (VBT) ${ }^{12,13}$ together with the thermodynamic difference rule (TDR), ${ }^{9,14-16}$ both of which we and colleagues have developed and fostered over the last two decades. These empirical procedures have proven to have great generality and utility, and have been widely implemented for ionic solids and liquids ${ }^{17}$ as also illustrated in a list of applications in the final section of this paper. One further very successful method is the "Simple Sum Approximation" (SSA) ${ }^{18}$ where the thermodynamic properties of a complex ionic, such as $\mathrm{MgSiO}_{3}$, is treated as a sum of its components, being the oxides $\mathrm{MgO}$ and $\mathrm{SiO}_{2}$ in this case.

Prediction basically relies on the combination, through the Gibbs relation, of enthalpy, $H$, and entropy, $S$, contributions: ${ }^{19}$

$$
\Delta G=\Delta H-T \Delta S
$$

VBT and TDR provide estimates of values of standard enthalpy, $\Delta_{\mathrm{f}} H^{\circ}$, standard entropy, $S_{298}^{\circ}$, and hence, via eqn (1) lead to the prediction of $\Delta_{\mathrm{f}} G^{\circ}$ for individual materials as well as $\Delta_{\mathrm{r}} G^{\circ}$ for a reaction of interest. It is often of little concern that such estimates may not be highly precise, since the purpose of thermodynamic prediction may, in many instances, simply be one of assessing synthetic feasibility or otherwise, i.e., simply whether $\Delta_{\mathrm{r}} G$ is negative (feasible) or positive (infeasible in principle, although a small positive value, say $\sim 20 \mathrm{~kJ} \mathrm{~mol}^{-1}$, does not preclude formation of useful proportions of product which can be extracted from the reaction system). ${ }^{20}$ Furthermore, experimentally-derived thermodynamic values themselves can have considerable uncertainties. ${ }^{21-23}$ The actual mathematics required is minimal yet quantitative interpretation results. This review summarises VBT, TDR, SSA, and single-ion additivity, and highlights many of their successes - indeed, the scope of their application has proved to be quite remarkable - and directs the reader to numerous applications where these procedures have played a significant role in yielding the thermodynamics.

In essence, VBT [together with its isomegethic ("equal size") rule, ${ }^{24}$ which vastly extends its application to new and hypothesised materials] relates the formula unit volumes, $V_{\mathrm{m}}$, of materials, however measured or estimated, to their thermodynamic quantities, thereby leading to practical prediction. TDR uses the differences between related materials to predict values for other similar materials, while the additive SSA and single-ion values (and also TDR, in a slightly more complex way) demonstrate that the properties of complex materials may be estimated by summing the corresponding properties of their component parts.

\section{Group additivity methods}

Group methods operate by assuming that a material (typically, but not exclusively, an organic molecule) contains independent entities (such as single bonds, double bonds, alcohol, amine, etc.) whose thermodynamic property values can be summed to produce a property value for the whole material, but supplemented

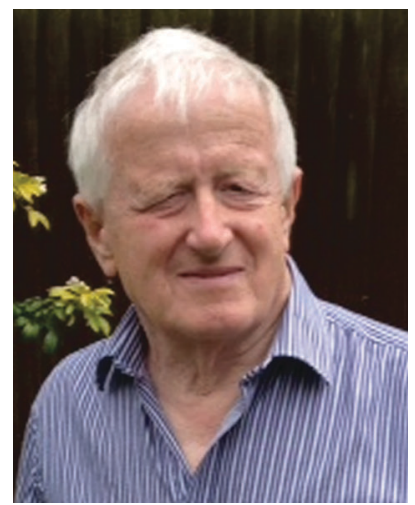

H. Donald Brooke Jenkins
Harry Donald Brooke Jenkins is Emeritus Professor of Chemistry, University of Warwick, U.K. International lecturer and researcher with ongoing projects in Spain, Perth and Switzerland, he was, with Glasser, founder of the VBT and TDR approaches. He is author of "Chemical Thermodynamics - at a glance" (Blackwell, Oxford), contributor to "Handbook of Chemistry and Physics" and to Nuffield Book of Data. His interests are bridge, foreign travel, playing the organ and painting. He has acted as consultant to numerous companies, large and small, and has held several Directorships. His love of the repertoire has led him to arrange international organ concerts. 
Table 1 Some empirical thermodynamic and volume rules

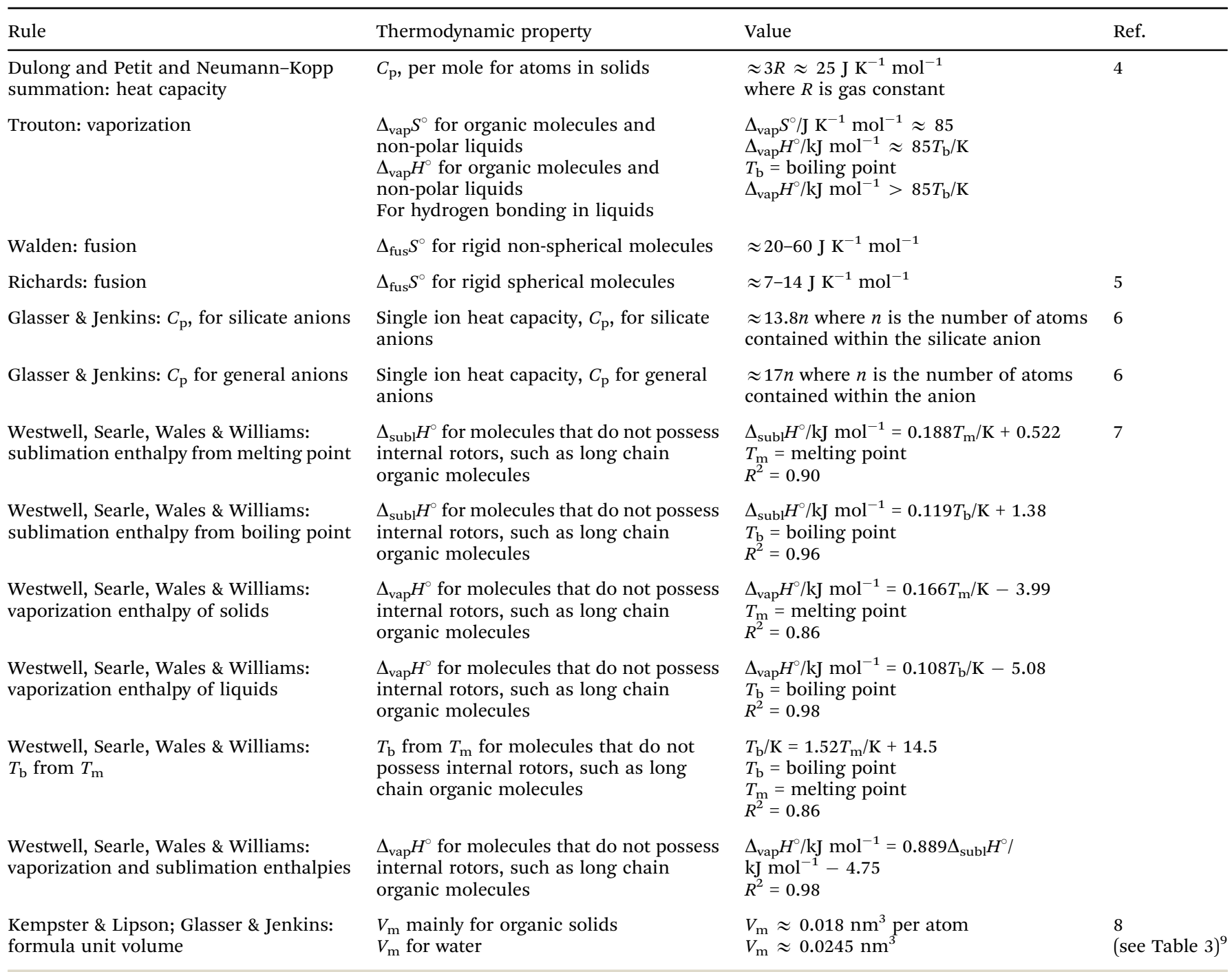

by other terms to allow for the interactions between and among groups. (An extensive list of group methods is presented in our ESI. $\dagger$ ) The most developed of these are termed Benson group methods. ${ }^{25}$ In order to permit broad application of the methods, it has been necessary to develop hundreds of group terms, with the further complication of the necessity for the user to identify suitable groups within the material under consideration. Many computer programs incorporate these methods, often as preliminary steps to a more complex analysis. The NIST WebBook ${ }^{26}$ provides a free service which implements the Benson group additivity scheme for gas-phase organic molecules.

Group methods have also been developed for ionic systems, by identifying constituent cations and anions whose properties are summed to provide the overall property value sought. The results are most reliable when based on related materials. In general, these methods have not received wide acceptance.

\section{Volume-based thermodynamics}

Early thermodynamic property-size relations were generally based upon ion radii since the alkali metal and halide monatomic ions of the most important alkali halides are spherical and radius, which could be quite readily established from X-ray data, was the most obvious measure of relative ion size. An important equation in this context was the Kapustinskii relation ${ }^{27}$ for lattice potential energy, $U_{\text {POT: }}$

$$
U_{\text {POT }}=\frac{A\left|\nu z_{+} z_{-}\right|}{\langle r\rangle}\left(1-\frac{\rho}{\langle r\rangle}\right)
$$

where $z_{+}, z_{-}$/electron units are the integer charges on the cations and anions, respectively, $\nu$ is the number of ions per formula unit, $\rho$ is a compressibility constant (usually chosen as $\rho=0.345 \mathrm{~nm}),\langle r\rangle$ is the sum of the cation and anion radii (which is often equated to the shortest cation-anion distance found in the lattice), and $A\left(=121.4 \mathrm{~kJ} \mathrm{~mol}^{-1} \mathrm{~nm}\right)$ is an electrostatic constant. While the contact distance, $\langle r\rangle$, between cation and anion is a straightforward sum for simple ions, it becomes ill-defined when complex ions are present. In addition to this conceptual problem, the Kapustinskii equation cannot be applied beyond binary materials because (i) there is no 
provision for more than one type of cation-anion contact, nor (ii) can more than a pair of charge types be accommodated.

Mallouk, Bartlett and coworkers ${ }^{28-31}$ presented some relationships between formula unit volume, $V_{\mathrm{m}}$ and thermodynamic properties (notably lattice energy, $U_{\mathrm{POT}}$, as a function of $V_{\mathrm{m}}{ }^{-1 / 3}$ ) and standard entropy, $S_{298}^{\circ}$ (as a function of $V_{\mathrm{m}}$ ) but only for a handful of MX (1:1) simple salts. Jenkins, Roobottom, Passmore and Glasser $^{32}$ explored these relationships further, by (i) replacing the distance sum with the equivalently-dimensioned cube-root of the formula unit volume, $V_{\mathrm{m}}{ }^{1 / 3}$, and (ii) using a generalisation of the charge product ${ }^{33}$ into an ionic strength factor-type summation, $I$ :

$$
\left|\nu z_{+} z_{-}\right| \Rightarrow \sum_{i} n_{i} z_{i}^{2}=2 I
$$

where $n_{i}=$ number of ions of type $i$ in the formula unit.

Scheme 1 summarises the processes and equations which use material volumes to produce thermodynamic values.

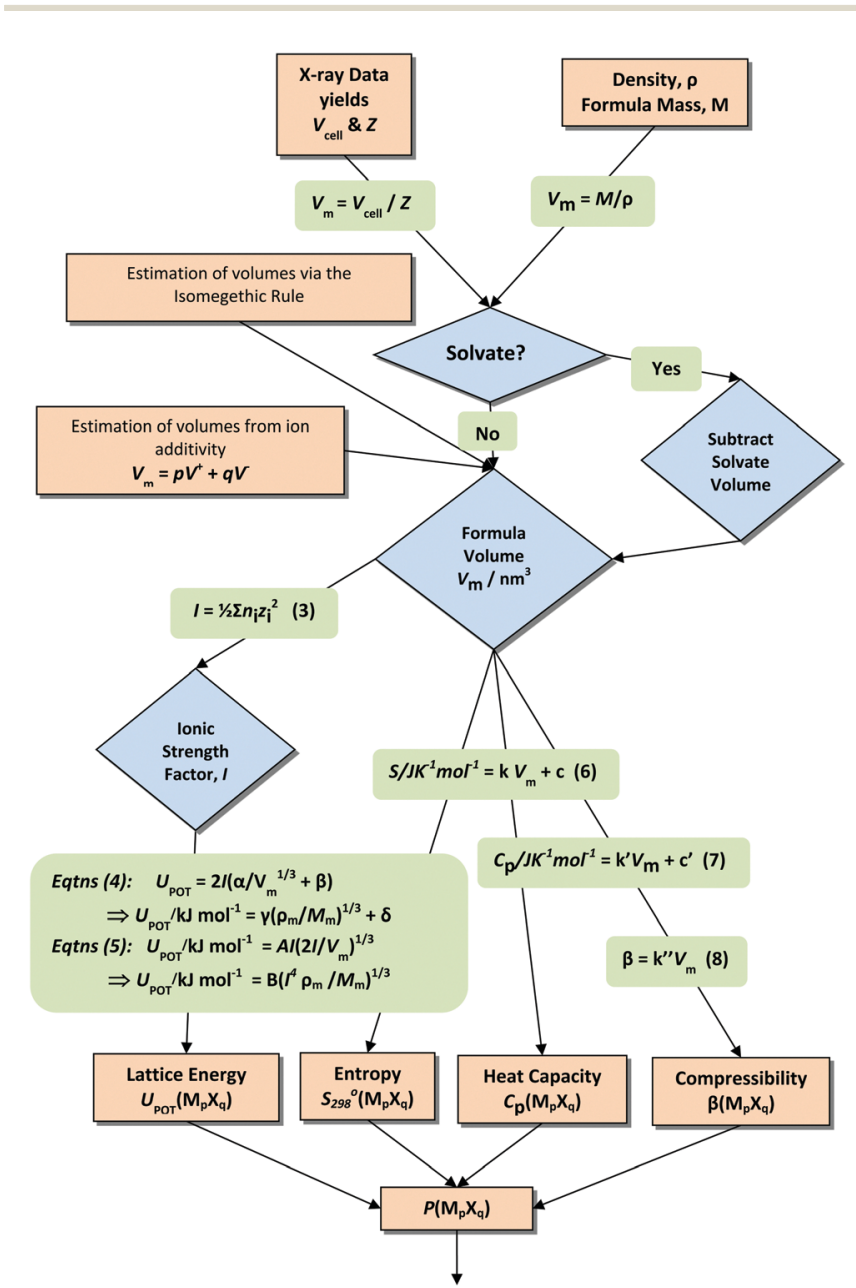

Scheme 1 Volume-based thermodynamics (VBT) flowchart. Data sources of various kinds are used to generate a formula unit volume, $V_{m}$, from which thermodynamic properties are estimated. $P\left(M_{p} X_{q}\right)$ represents any thermodynamic property, $P$, of the material $M_{p} X_{q} . \alpha, \beta, \gamma, \delta, A, B, k, c, c^{\prime}, k^{\prime}$ and $k^{\prime \prime}$ represent various constants obtained by fitting to experimental data. Eqn (4)-(8) appear in this scheme.
Lattice energies for a large database of simple ionic solids could be reliably correlated using this linear VBT function: ${ }^{34}$

$$
U_{\mathrm{POT}}=2 I\left(\frac{\alpha}{V_{\mathrm{m}}^{1 / 3}}+\beta\right)
$$

where $\alpha$ and $\beta$ are empirical constants which differ depending on stoichiometry, and have been determined by fitting to extensive experimental data. ${ }^{32}$ It is noteworthy that the fitted constant, $\alpha$, is found always to be close in value to the electrostatic factor, $A$, in eqn (2), above.

Equivalent equations may be couched in terms of density, $\rho_{\mathrm{m}}$, and formula mass, $M_{\mathrm{m}}$ :

$$
\begin{array}{cc}
U_{\mathrm{POT}} / \mathrm{kJ} \mathrm{mol}^{-1}=\gamma\left(\rho_{\mathrm{m}} / M_{\mathrm{m}}\right)^{1 / 3}+\delta & (4, \text { Scheme } 1) \\
U_{\mathrm{POT}} / \mathrm{kJ} \mathrm{mol}^{-1}=B\left(I^{4} \rho_{\mathrm{m}} / M_{\mathrm{m}}\right)^{1 / 3} & (5, \text { Scheme } 1)
\end{array}
$$

where $B$ is a combined constant.

For lattice energies greater than $5000 \mathrm{~kJ} \mathrm{~mol}^{-1}$, which includes most minerals, a limiting version ${ }^{35}$ of this equation exists which contains no empirical constants whatsoever and yet satisfactorily predicts lattice energies up to $70000 \mathrm{~kJ} \mathrm{~mol}^{-1}$ and probably beyond:

$$
U_{\mathrm{POT}}=A I\left(2 I / V_{\mathrm{m}}\right)^{1 / 3} \quad(5, \text { Scheme } 1)
$$

Lattice energy is readily converted to lattice enthalpy ${ }^{36}$ (as it needs to be if it is to be included in an enthalpy-based thermochemical cycle such as that in Fig. 1 below) using the equation:

$$
\Delta_{\mathrm{L}} H=U_{\mathrm{POT}}+\sum_{i=1}^{n} s_{i}\left(\frac{c_{i}}{2}-2\right) R T
$$

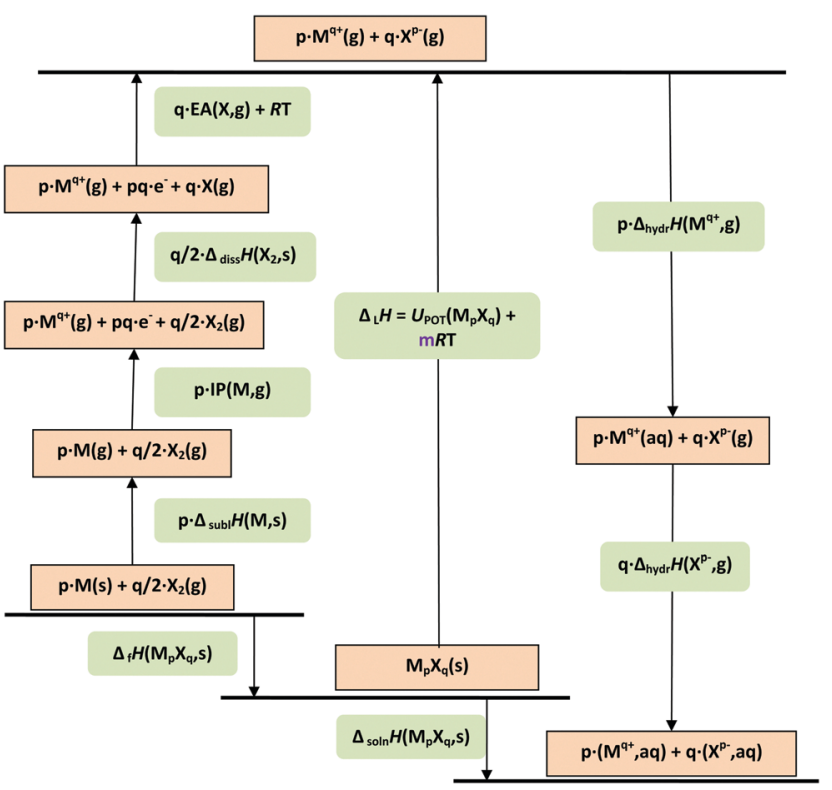

Fig. 1 Born-Haber-Fajans cycle for solids and aqueous solutions of formula $M_{p} X_{q} . I P=$ ionisation potential; $E A=$ electron affinity; lattice enthalpy $\left(\Delta_{\mathrm{L}} H\right)$ and enthalpies of formation $\left(\Delta_{f} H\right)$, sublimation $\left(\Delta_{\text {subl }} H\right)$, dissociation $\left(\Delta_{\text {diss }} H\right)$, hydration $\left(\Delta_{\text {hydr }} H\right)$, and solution $\left(\Delta_{\text {soln }} H\right)$ are involved. $U_{\text {POT }}$ represents the lattice potential energy. In the formula for $\Delta_{\mathrm{L}} H, m$ depends on $p$ and $q$ and the nature of the ions $\mathrm{M}^{q+}$ and $\mathrm{X}^{q-}$ (see eqn (9) in text). ${ }^{36}$ 


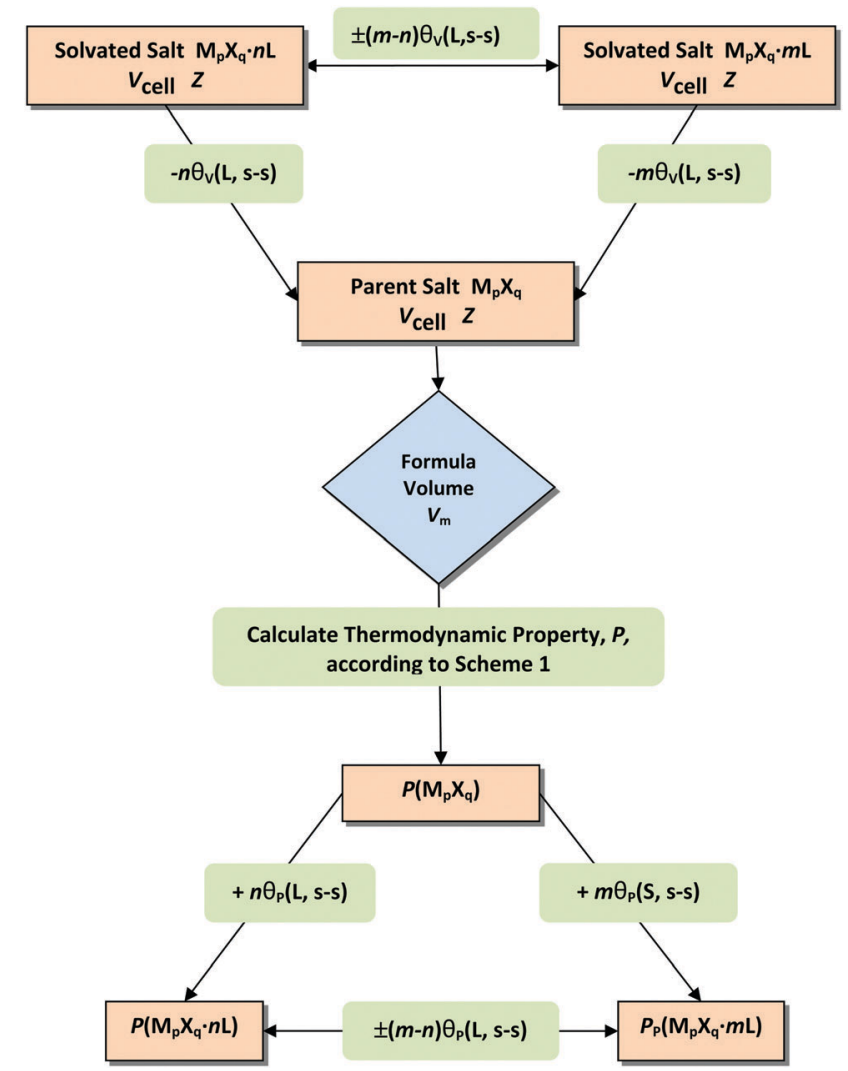

Scheme 2 Thermodynamic difference rule (TDR) flowchart. The volume of addend or solvate, $L$, is subtracted to generate the volume of the parent material:

$$
V\left(\mathbf{M}_{p} \mathbf{X}_{q} \cdot n L\right)-n V(L)=V\left(\mathbf{M}_{p} \mathbf{X}_{q}\right)
$$

from which the thermodynamic property, $P$, is calculated. Finally, the thermodynamic property value, $\theta_{P}(L, s-s)$, of the addend or solvent (which may be water) is added (where " $s-s$ " represents that the difference, $\theta_{P}$, between materials each in the same phase, often solid).

where $\Delta_{\mathrm{L}} H$ is the lattice enthalpy, $n$ is the number of ion types in the formula unit, $s_{i}$ is the number of ions of type $i$, and $c_{i}$ is defined according to whether ion $i$ is monatomic $\left(c_{i}=3\right)$, linear polyatomic $\left(c_{i}=5\right)$, or nonlinear polyatomic $\left(c_{i}=6\right)$.

Using these approaches, it becomes simple to evaluate the lattice energies, $U_{\text {РОт }}$ (and enthalpies of formation, $\Delta_{\mathrm{f}} H^{\circ}$, via the Born-Haber-Fajans relation) of ionic solids.

\section{Thermodynamic difference rule (TDR)}

The thermodynamic difference rule, TDR, is a complementary set of procedures which utilizes additive connections among related materials. ${ }^{9,12-16}$ Scheme 2 shows the steps by which TDR is usually applied. The technique is extremely powerful as a result of its ability to enable estimates to be made of thermodynamic data not otherwise available.

$$
\begin{gathered}
P\left(\mathbf{M}_{p} \mathbf{X}_{q} \cdot n L, \mathbf{s}\right)-P\left(\mathbf{M}_{p} \mathbf{X}_{q}, \mathbf{s}\right)=n \theta_{P}(L, \mathrm{~s}-\mathrm{s}) \\
P\left(\mathbf{M}_{p} \mathbf{X}_{q} \cdot m L, \mathbf{s}\right)-P\left(\mathbf{M}_{p} \mathbf{X}_{q} \cdot n L, \mathbf{s}\right)=(m-n) \theta_{P}(L, \mathrm{~s}-\mathbf{s})
\end{gathered}
$$

Thus, various thermodynamic state properties may be estimated as, for example, the lattice energies of hydrates using the thermodynamic difference rule relation:

$$
U_{\text {РОT }}\left(\mathrm{M}_{p} \mathrm{X}_{q} \cdot n \mathrm{H}_{2} \mathrm{O}, \mathrm{c}\right)-U_{\text {РОT}}\left(\mathrm{M}_{p} \mathrm{X}_{q}, \mathrm{c}\right)=n \theta_{\mathrm{U}}\left(\mathrm{H}_{2} \mathrm{O}\right)
$$

with $\theta_{\mathrm{U}}\left(\mathrm{H}_{2} \mathrm{O}\right)=54.3 \mathrm{~kJ} \mathrm{~mol}^{-1}$, as empirically determined. Table 2 lists values for the fitted constants for various groups of materials, while Table 3 lists values pertaining to the hydrate TDR rules. TDR constants for other solvates may be found in Table 1 in the literature referenced. ${ }^{9}$ An important recent paper considers the thermodynamics of hydration in minerals. ${ }^{37}$

\section{Room-temperature ionic liquids}

Room-temperature ionic liquids (RTILs) ${ }^{38-41}$ can replace organic solvents used for the dissolution of both polar and non-polar solutes and for processing or extraction of materials, while also having useful catalytic features. ${ }^{42}$ ILs are low-polluting, with low combustibility, good thermal stability and low vapour pressures. They have high viscosities, and their liquid range can often cover several hundred degrees. The range of their applications has been extended by use of mixtures of IL's ${ }^{43}$ and as supercritical fluids. ${ }^{44}$

As their name implies, they are usually liquid at ambient temperatures and consist solely of ionic species. In order to reduce the lattice energy of their crystalline state and hence their melting point, one or sometimes both of their cations and anions need to be large and their cations also often have low symmetry. The cations are generally organic with long-chain features and buried charges, such as the pyrollidinium, methylimidazolium and pyridinium cations (see Fig. 2) while the anions, such as $\mathrm{BF}_{4}{ }^{-}, \mathrm{PF}_{6}{ }^{-}$, or $\mathrm{NTf}_{2}{ }^{-}$[formula: $\left(\mathrm{CF}_{3} \mathrm{SO}_{2}\right)_{2} \mathrm{~N}^{-}$] have diffuse charges.

Since there are, as noted above, many possible combinations of cation and anion, it becomes possible to consider designing ionic liquids to purpose. Although early QSAR predictions ${ }^{45-47}$ were not always regarded as satisfactory, ${ }^{48}$ molecular volume ${ }^{49}$ has emerged as an important observable. Thus, Glasser ${ }^{38}$ has estimated a VBT-based entropy for ionic liquids, derived from correlations for both inorganic solids and organic liquids:

$$
S\left(\mathrm{~J} \mathrm{~K}^{-1} \mathrm{~mol}^{-1}\right)=1246.5\left(V_{\mathrm{m}} / \mathrm{nm}^{3}\right)+29.5
$$

Similarly, Gutowski, et al., ${ }^{50-52}$ have developed a lattice energy correlation for 1:1 ionic liquids, with amended constants (eqn (4), Scheme 1): $I=1, \alpha=8326 \mathrm{~kJ} \mathrm{~nm} \mathrm{~mol}^{-1}$ and $\beta=157 \mathrm{~kJ} \mathrm{~mol}^{-1}$.

VBT relations have now been used to establish other physical thermodynamic properties, independent of crystal structure, such as liquid entropy, ${ }^{53}$ melting point, ${ }^{54-56}$ heat capacity ${ }^{57}$ and critical micelle concentration (c.m.c.). ${ }^{58}$ A recent review by Beichel $^{59}$ cites relevant literature from the Krossing laboratory; in order to emphasize lack of reliance on any experimental input at all, this group has introduced the term "augmented volumebased thermodynamics".

\section{An explanation for the simple volume relations}

The striking simple relations to volume involved in VBT, almost independent of structure, upon which we have reported invite some explanation. We suggest that the bulk thermodynamic 
Table 2 Constants for a selection of volume-based thermodynamic relations

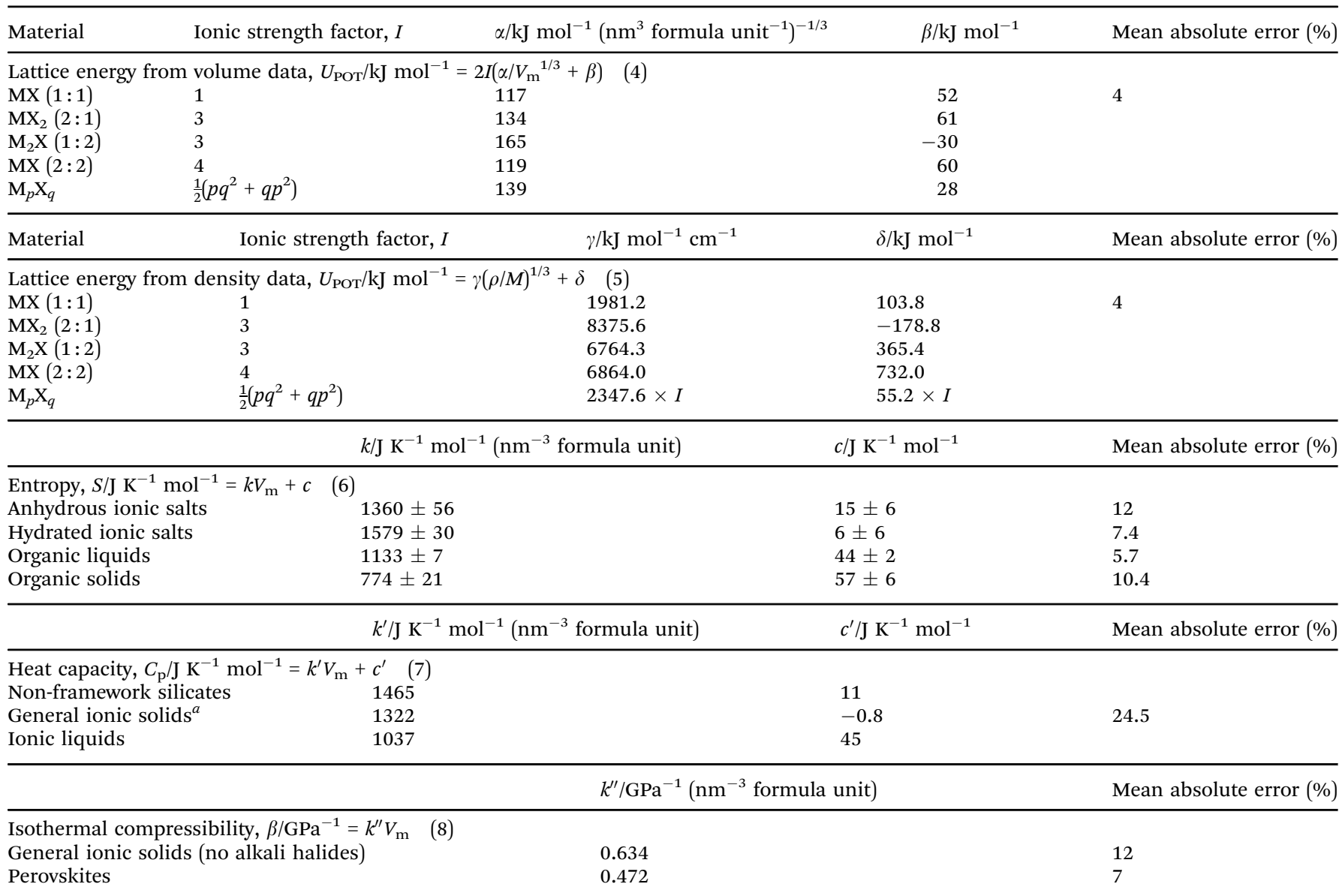

${ }^{a} C_{\mathrm{p}}$ values have been estimated for 799 materials, ranging from small ionics to large mineral structures. Poor outliers may be avoided by using the lesser of the calculated value from eqn (7) and the approximate limiting Dulong-Petit value of $25 \times m \mathrm{~J} \mathrm{~K}^{-1} \mathrm{~mol}^{-1}$, where $m=$ number of atoms in the formula unit ( $c f$. Table 1).

Table 3 Thermodynamic difference values, $\theta_{P}$, for hydrates for property $P: P\left(\mathrm{M}_{p} \mathrm{X}_{q} \cdot n \mathrm{H}_{2} \mathrm{O}\right)-P\left(\mathrm{M}_{p} \mathrm{X}_{q}\right)=n \theta_{P}\left(\mathrm{H}_{2} \mathrm{O}, \mathrm{s}-\mathrm{s}\right)^{a}$

\begin{tabular}{|c|c|}
\hline Thermodynamic property, $P$ & $\theta_{P}{ }^{9}$ \\
\hline$V_{\mathrm{m}} / \mathrm{nm}^{3}\left(\mathrm{~mol} \text { of } \mathrm{H}_{2} \mathrm{O}\right)^{-1}$ & 0.0245 \\
\hline$U_{\mathrm{POT}} / \mathrm{kJ}\left(\mathrm{mol} \text { of } \mathrm{H}_{2} \mathrm{O}\right)^{-1}$ & 54.3 \\
\hline$\Delta_{\mathrm{f}} H / \mathrm{kJ}\left(\mathrm{mol} \text { of } \mathrm{H}_{2} \mathrm{O}\right)^{-1}$ & -298.6 \\
\hline$\Delta_{\mathrm{f}} S / \mathrm{J} \mathrm{K} \mathrm{K}^{-1}\left(\mathrm{~mol} \text { of } \mathrm{H}_{2} \mathrm{O}\right)^{-1}$ & -192.4 \\
\hline$\Delta_{\mathrm{f}} G / \mathrm{kJ}\left(\mathrm{mol} \text { of } \mathrm{H}_{2} \mathrm{O}\right)^{-1}$ & -242.4 \\
\hline$S_{298}^{\circ} / \mathrm{J} \mathrm{K}^{-1}\left(\mathrm{~mol} \text { of } \mathrm{H}_{2} \mathrm{O}\right)^{-1}$ & 40.9 \\
\hline$C_{\mathrm{p} 298}^{\circ} / \mathrm{J} \mathrm{K}^{-1}\left(\mathrm{~mol} \text { of } \mathrm{H}_{2} \mathrm{O}\right)^{-1}$ & $42.8^{16}$ \\
\hline
\end{tabular}

${ }^{a}$ A more complete table, including values of $\theta_{P}$ for solvates other than $\mathrm{H}_{2} \mathrm{O}$, has been published. ${ }^{16}$

properties derive from the interactions between the particles involved (complex ions or even molecules) rather than within those particles. ${ }^{60}$ For ionic materials, the interactions are largely coulombic (electrostatic or Madelung energies) with lesser contributions from specific repulsion and van der Waals-type interactions so that (to the approximation inherent in our correlations) the interactions are similar, independent of the specific species involved and also independent of structure. At this level of approximation we have<smiles></smiles>

(I)<smiles>[R][P+]([R])([R])[R]</smiles>

(IV)<smiles>[R][n+]1ccccc1</smiles>

(II)<smiles>[R][N+]([R])([R])[R]</smiles>

(III)
Fig. 2 Principal cations involved in important ionic liquids. (I) Imidazolium cations, (II) pyridinium cations, (III) tetraalkylammonium cations, (IV) tetraalkylphosphonium cations, and (V) pyrollidinium cations.

found that the thermodynamic values that emerge prove adequate, in the majority of cases, for deciding questions of alternative synthetic routes for the preparation of inorganic materials. 


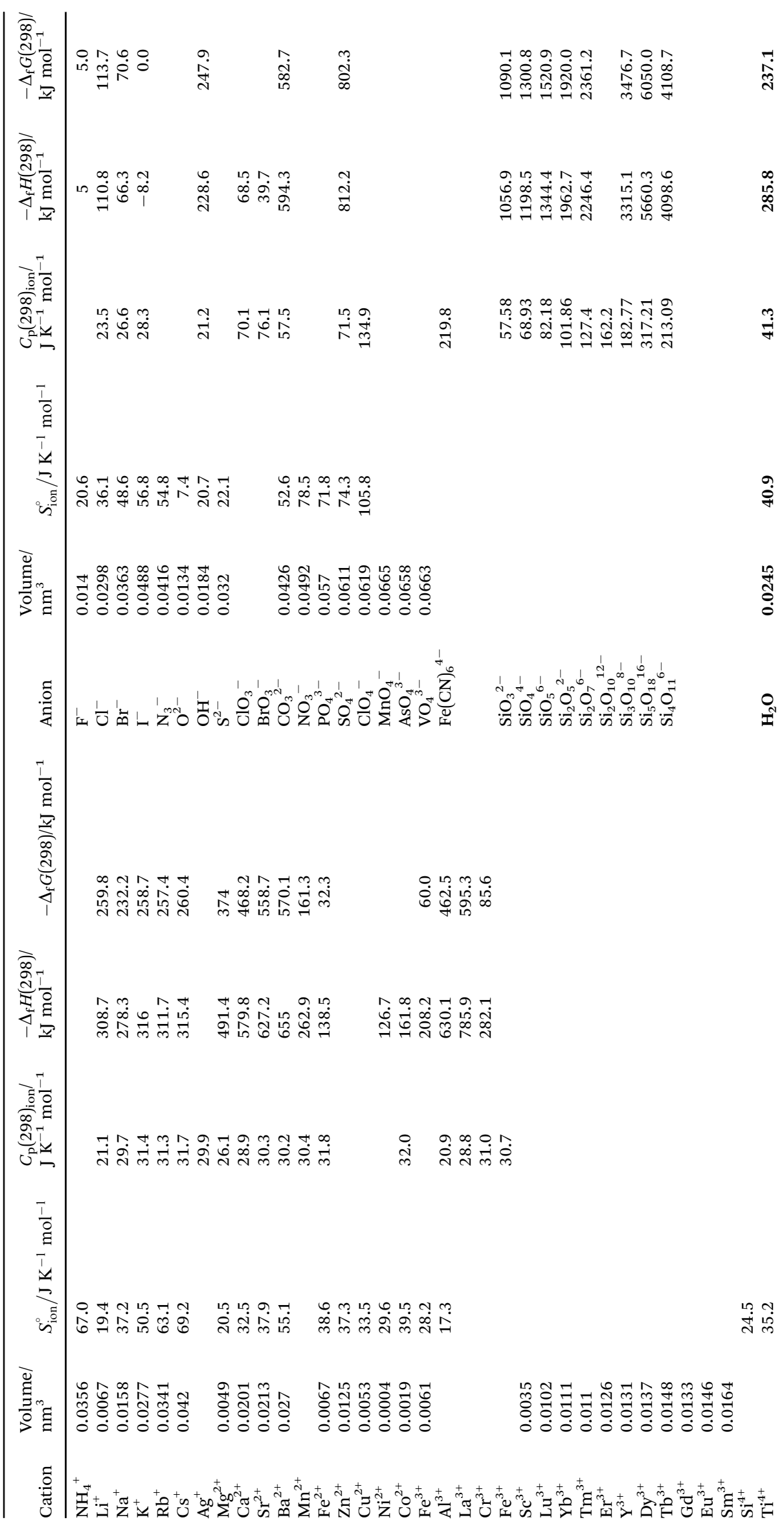


As we have noted above, an important consequence of the independence of structure is that these relations apply equally to pure liquids as to solids, so that they can be applied to the increasingly important class of ionic liquids. ${ }^{38}$

\section{Madelung energies - for known structures}

The coulombic (or Madelung) energy, $E_{\mathrm{M}}$, of a material of known structure is readily calculated by means of standard computer programs, such as GULP ${ }^{61}$ and EUGEN. ${ }^{62}$ This energy corresponds to separating the constituent ions into independent gas phase ions against coulombic forces only. We have observed $^{63}$ that the resulting Madelung energy is closely related to the corresponding lattice energy, in the form

$$
U_{\mathrm{POT}} / \mathrm{kJ} \mathrm{mol}^{-1}=0.8518 E_{\mathrm{M}}+293.9
$$

Eqn (14) thus provides a further simple direct means for obtaining lattice energies, apart from VBT. However, the Madelung calculation comes into its own when applied to an ionic system with structures containing covalently-bonded complexes, such as $\mathrm{K}_{2} \mathrm{SnCl}_{6}$. If the complex ion, $\mathrm{SnCl}_{6}{ }^{2-}$ in this case, is treated as a "condensed ion", with all the ion charge placed on the central atom (thus $\mathrm{Sn}^{2-}$ ) and the ligands given zero charge $\left(\mathrm{Cl}^{0}\right)$, then we are effectively dealing with a system which decomposes to $2 \mathrm{~K}^{+}(\mathrm{g})+$ $\mathrm{Sn}^{2-}(\mathrm{g})$ when the Madelung energy, now $E_{\mathrm{M}}{ }^{\prime}$, is supplied. For this system

$$
U_{\mathrm{POT}} / \mathrm{kJ} \mathrm{mol}^{-1}=0.963 E_{\mathrm{M}}^{\prime}
$$

From these values, we can determine a formation energy for the "condensed ion" complex (see example below).

\section{Isomegethic rule}

Our isomegethic ("equal size") rule ${ }^{24}$ states that "ionic salts of the same empirical chemical formula having identical charge states (i.e., lattice ionic strength factors, $I$ ) will have approximately equal formula unit volumes, $V_{\mathrm{m}}$." Since $I, V_{\mathrm{m}}$ and stoichiometry are then approximately identical, isomegethic compounds will have almost identical lattice potential energies too.

As an illustration, consider the relation:

$$
V_{\mathrm{m}}\left(\mathrm{NO}^{+} \mathrm{ClO}_{4}{ }^{-}\right) \approx V_{\mathrm{m}}\left(\mathrm{NO}_{2}{ }^{+} \mathrm{ClO}_{3}{ }^{-}\right) \approx V_{\mathrm{m}}\left(\mathrm{ClO}_{2}{ }^{+} \mathrm{NO}_{3}{ }^{-}\right)
$$

and hence:

$$
U_{\mathrm{POT}}\left(\mathrm{NO}^{+} \mathrm{ClO}_{4}^{-}\right) \approx U_{\mathrm{POT}}\left(\mathrm{NO}_{2}^{+} \mathrm{ClO}_{3}^{-}\right) \approx U_{\mathrm{POT}}\left(\mathrm{ClO}_{2}^{+} \mathrm{NO}_{3}^{-}\right)
$$

Good examples of the scope of the isomegethic rule in providing multiple estimates for the volumes of ions are given in detail in ref. 24 and 64. Relations of this kind provide enormous scope for estimation of formula unit volumes and lattice energies, which is especially useful for hypothesised materials. If the enthalpies of formation of the individual gaseous component ions are known ${ }^{65,66}$ then the enthalpy of formation of the isomegethic compound may usually be estimated, thus taking us into the full compass of the thermodynamics of the material concerned.

\section{Single-ion values}

Since it is seldom that all the desired thermodynamic values are available to generate the desired data, we have prepared sets of internally consistent single-ion values which may be used additively to generate otherwise absent data, collected in Table 4. An early example of this procedure is provided by the work of Latimer ${ }^{67,68}$ in developing single ion entropy estimates.

\section{An example set of predictive thermodynamic calculations: $\mathrm{K}_{2} \mathrm{SnCl}_{6}$}

We here provide a set of results for the material dipotassium hexachlorostannate, $\mathrm{K}_{2} \mathrm{SnCl}_{6}$, where we have deliberately selected the difficult case of a partially covalent material for which experimental thermodynamic values are available for comparison. This demonstrates some of the weaknesses of these predictive methods against some of their strengths in that they may provide a wide range of otherwise unavailable thermodynamic values.

Simple salt approximation (SSA). Table 5 demonstrates the features of the "Simple Salt Approximation" in generating results by combining reaction components.

For the SSA to be accurate, it is necessary that the reaction to form product should yield zero (or small) thermodynamic differences. As may be seen from the final column in Table 5, the reaction $2 \mathrm{KCl}+\mathrm{SnCl}_{4} \rightarrow \mathrm{K}_{2} \mathrm{SnCl}_{6}$ produces non-zero differences, so that the SSA results (3rd last column) are not accurate, but may be useful as a general guide when the thermodynamic values are unknown.

Volume-based thermodynamics (VBT). VBT is a specifically ionic-based set of empirical procedures, correlated against strongly ionic materials such as simple halides and more complex oxides. We examine its application to $\mathrm{K}_{2} \mathrm{SnCl}_{6}$ with its covalent central ion, $\mathrm{SnCl}_{6}{ }^{2-}$.

The constants used in the following calculations are selected from Table 2.

(a) Formula unit volume, ${ }^{70} V_{\mathrm{m}} / \mathrm{nm}^{3}=V_{\text {cell }} / Z=1.0057 / 4=0.2514$

(b) Ionic strength factor, $I=1 / 2 \sum n_{i} z_{i}^{2}=3$ (eqn (3))

(c) Lattice (potential) energy, $U_{\mathrm{POT}} / \mathrm{kJ} \mathrm{mol}^{-1}=2 I\left(\alpha / V_{\mathrm{m}}{ }^{1 / 3}+\beta\right)$ $($ eqn $(4))=2 \times 3\left(165 / 0.2514^{1 / 3}-30\right)=1389(c f$. Born-Haber-Fajans cycle value vi $^{71}$ 1390, Fig. 3$)$

Table 5 Additive thermodynamic values for $\mathrm{K}_{2} \mathrm{SnCl}_{6}$, following the "Simple Salt Approximation". ${ }^{18}$ Data (columns 2, 3, 4 and 7) from HSC Chemistry $8^{69}$

\begin{tabular}{lrrrrrr}
\hline & \multicolumn{1}{c}{$\mathrm{KCl}$} & \multicolumn{1}{c}{$\mathrm{SnCl}_{4}$} & $\mathrm{~K}_{2} \mathrm{SnCl}_{6}$ & $2 \mathrm{KCl}+\mathrm{SnCl}_{4}$ & ${ }^{2} \mathrm{Diff}$ & $2 \mathrm{KCl}^{2} \mathrm{SnCl}_{4} \rightarrow \mathrm{K}_{2} \mathrm{SnCl}_{6}$ \\
\hline$\Delta_{\mathrm{f}} H^{\circ}\left(25{ }^{\circ} \mathrm{C}, \mathrm{s}\right) / \mathrm{kJ} \mathrm{mol}^{-1}$ & -436.7 & -517.0 & -1482.0 & -1390.4 & -6.2 & -91.6 \\
$S^{\circ}\left(25^{\circ} \mathrm{C}, \mathrm{s}\right) / \mathrm{J} \mathrm{K} \mathrm{mol}^{-1}$ & 82.7 & 265.0 & 371.0 & 430.4 & 16.0 & -59.4 \\
$\Delta_{\mathrm{f}} G^{\circ}\left(25^{\circ} \mathrm{C}, \mathrm{s}\right) / \mathrm{kJ} \mathrm{mol}^{-1}$ & -461.3 & -596.0 & -1592.6 & -1518.7 & -4.6 & -73.9 \\
$C_{\mathrm{p}}\left(25^{\circ} \mathrm{C}, \mathrm{s}\right) / \mathrm{J} \mathrm{K}{ }^{-1} \mathrm{~mol}^{-1}$ & 51.4 & 157.2 & 221.1 & 260.1 & 17.6 & -39.0
\end{tabular}


(d) Standard entropy, $S / \mathrm{J} \mathrm{K}^{-1} \mathrm{~mol}^{-1}=k V_{\mathrm{m}}+c$ (eqn (6)) $=1360 \times$ $0.2514+15=356.9$ (cf. 371.0, diff. 3.9\%, Table 5)

(e) Heat capacity, $C_{\mathrm{p}} / \mathrm{J} \mathrm{K}^{-1} \mathrm{~mol}^{-1}=k^{\prime} V_{\mathrm{m}}+c^{\prime}($ eqn $(7))=1322 \times$ $0.2514-0.8=331.6$ (cf. 221.1, diff. $-33 \%$, Table 5) (NeumannKopp atom additive value ${ }^{6}$ for 9 atoms $=25 \times 9=225$ : diff. $1.7 \%$ )

Comment: the VBT value calculated for $C_{\mathrm{p}}$ considerably exceeds the 9-atom limiting Neumann-Kopp value, which we propose is a preferred value (see Table 2). This suggests that the rigid covalent $\mathrm{SnCl}_{6}{ }^{2-}$ structure corresponds to too-large a volume compared with a close-packed strictly ionic system. Correspondingly, the predicted entropy is also too large. By contrast, in calculating the lattice energy, any volume error is minimised by the use of a cube-root volume.

(f) $\Delta_{\mathrm{f}} H\left(\mathrm{SnCl}_{6}{ }^{2-}, \mathrm{g}\right) / \mathrm{kJ} \quad \mathrm{mol}^{-1}=U_{\mathrm{POT}}\left(\mathrm{K}_{2} \mathrm{SnCl}_{6}, \mathrm{~s}\right)^{71}+$ $\Delta_{\mathrm{f}} H\left(\mathrm{~K}_{2} \mathrm{SnCl}_{6}, \mathrm{~s}\right)^{69}-2 \Delta_{\mathrm{f}} H\left(\mathrm{~K}^{+}, \mathrm{g}\right)^{71}=(1390)+(-1482)-2(514)=$ $-1120\left(c f^{65}-1156\right.$, diff. $\left.3.1 \%\right)$

(g) Madelung energy ${ }^{72}$ for $\mathrm{K}_{2} \mathrm{SnCl}_{6}(\mathrm{~s}), E_{\mathrm{M}} / \mathrm{kJ} \mathrm{mol}^{-1}=9322$ converted to $U_{\mathrm{M}} / \mathrm{kJ} \mathrm{mol}^{-1}=0.8518 \times 9322+293.9=8234$

Comment: see Born-Haber-Fajans cycle, Fig. 3.

(h) Madelung energy, assuming the "condensed ion",72 $\mathrm{SnCl}_{6}{ }^{2-}, E_{\mathrm{M}}{ }^{\prime} / \mathrm{kJ} \mathrm{mol}^{-1}=1613.7$ converted to $U_{\mathrm{POT}} / \mathrm{kJ} \mathrm{mol}^{-1}=$ $0.963 \times 1614=1554$

Comment: this result may be compared with the value noted in (c) above of $1390 \mathrm{~kJ} \mathrm{~mol}^{-1}(+11 \%)$.

Comment: see Born-Haber-Fajans cycle, Fig. 3.

(i) By difference, dissociation energy to independent ions, $\Delta_{\text {diss }} H\left(\mathrm{SnCl}_{6}{ }^{2-}, \mathrm{g}\right)=5199 \mathrm{~kJ} \mathrm{~mol}^{-1}$

Comment: this is a "new" value, not previously reported.

(j) Lattice energy $/ \mathrm{kJ} \mathrm{mol}^{-1}$ to form independent gaseous ions $2 \times \mathrm{K}^{+}\left(\Delta_{\mathrm{f}} H=2 \times 541.0\right),{ }^{69} 6 \times \mathrm{Cl}^{-}\left(\Delta_{\mathrm{f}} H=6 \times-227.6\right),{ }^{69}$ and $\operatorname{Sn}^{4+}\left(\Delta_{\mathrm{f}} H=9320.7\right)^{65}=7501$, diff. $10 \%$ from $(\mathrm{g})$.

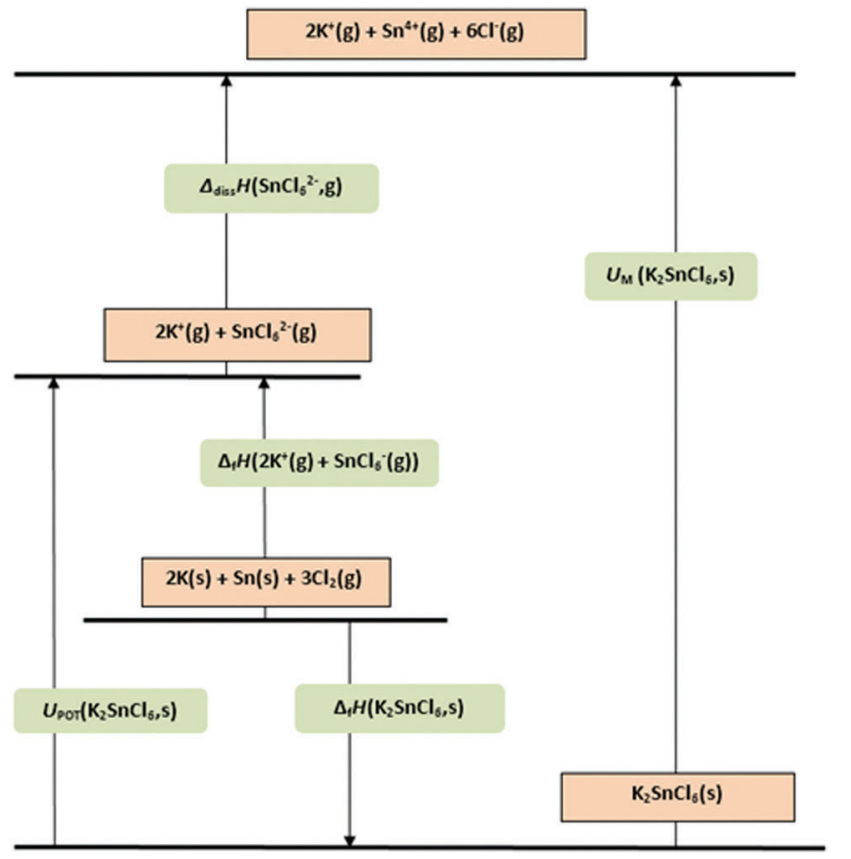

Fig. 3 Born-Haber-Fajans cycle for $\mathrm{K}_{2} \mathrm{SnCl}_{6}$.

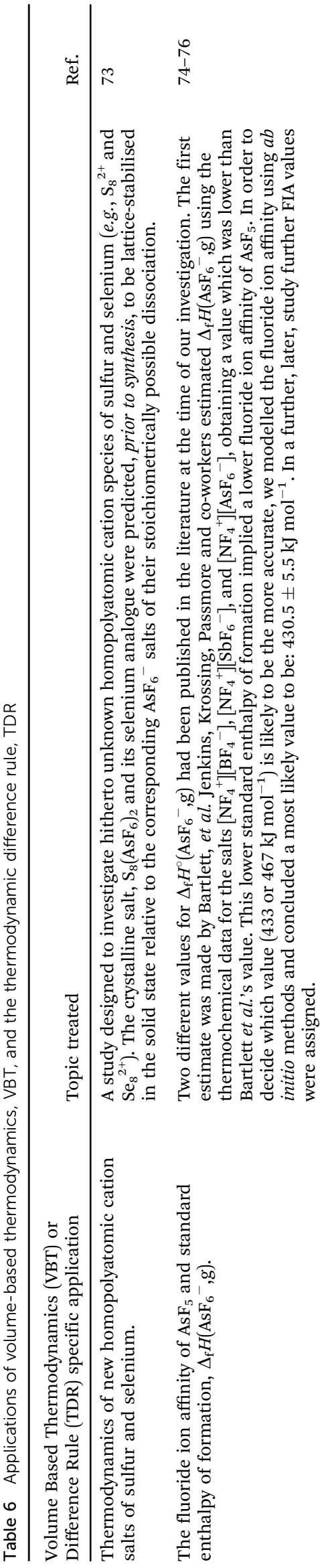

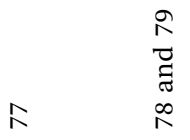

$\because \infty$

西:

สำ

3 这

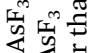

ये के

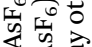

का

䒕岁要

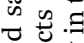

总

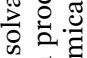

至 율

ఫृ

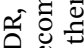

둥

‡ั

佂

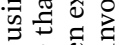

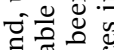

ت

莺

通范

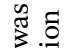

늘 응

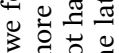

됼

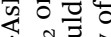

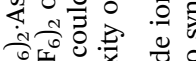

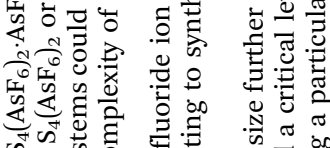

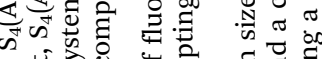

战视

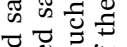

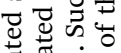

至

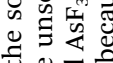

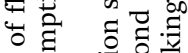

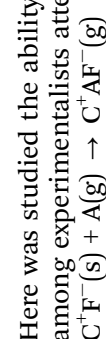

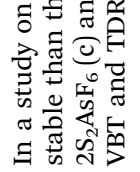

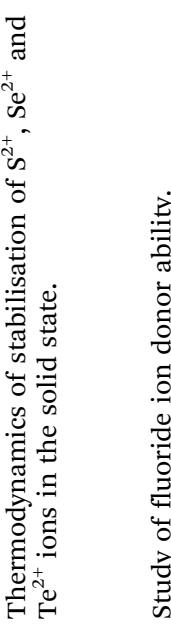


PCCP

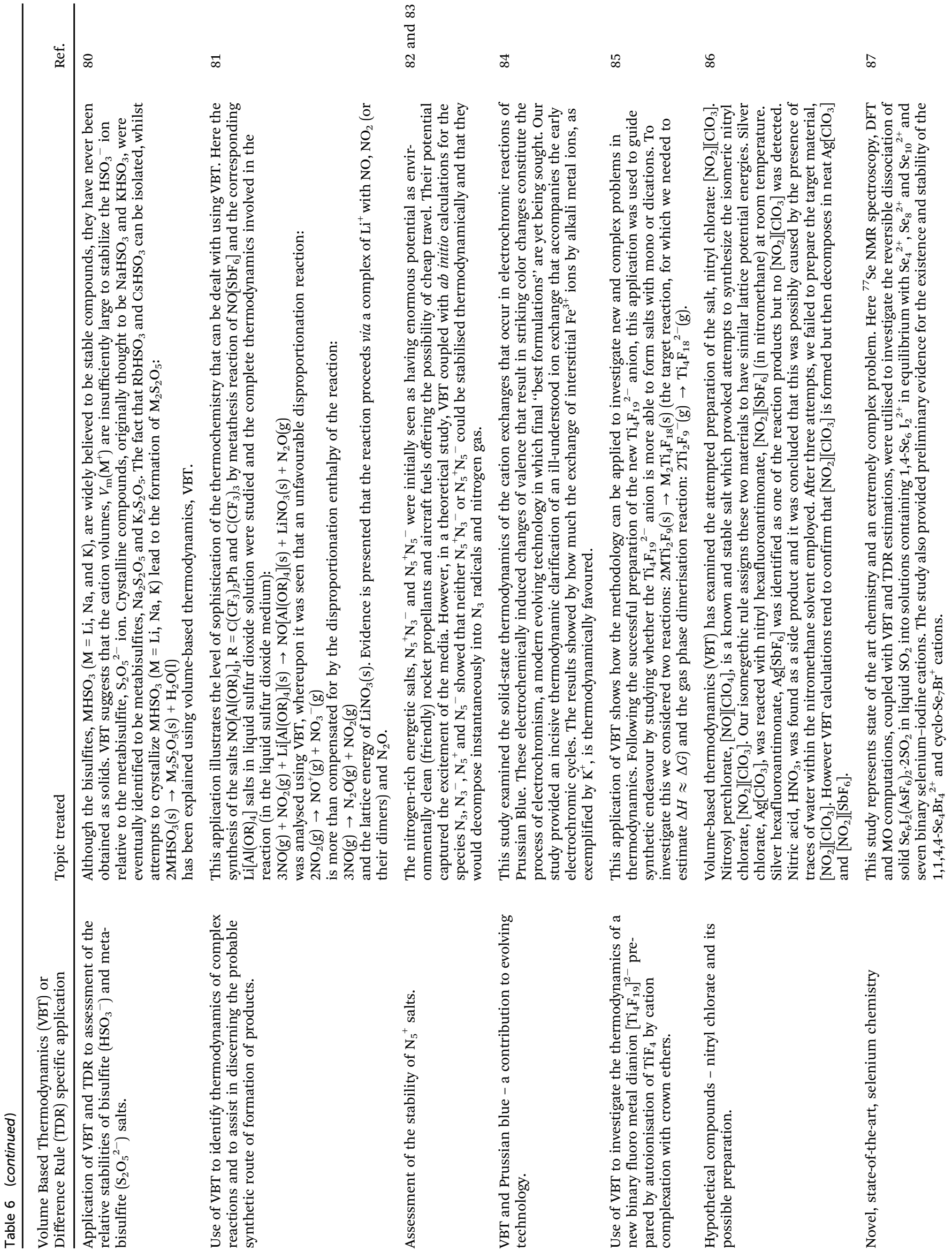




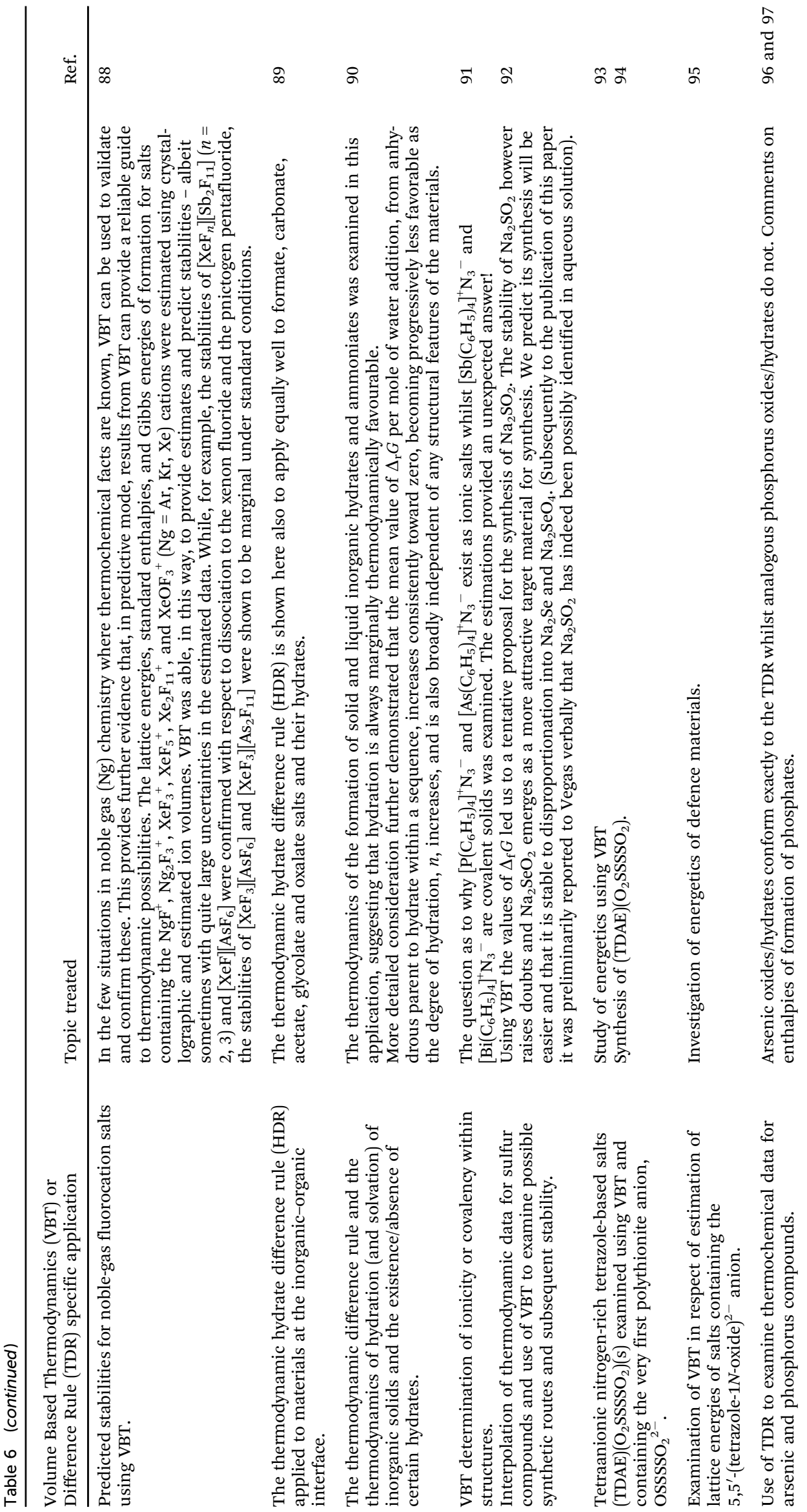




\section{Conclusion}

Neither volume-based thermodynamics (VBT) nor the thermodynamic difference rule (TDR), together with their supporting quantities, require a high level of computational expertise nor expensive high-performance computation tools - a spreadsheet will usually suffice - yet the techniques are extremely powerful and accessible to non-experts. Table 2 summarises correlation equations between formula unit volume, $V_{\mathrm{m}}$, and various thermodynamic properties, together with measures of anticipated errors. These correlation equations provide ready access to otherwise unavailable thermodynamic data, as also rapid checks of published data. The results should always be treated with appropriate caution by checking against known values for related materials.

\section{Applications of volume-based thermodynamics, VBT, and the thermodynamic difference rule, TDR}

In rough chronological order, we present a selection of applications of VBT and TDR which have enabled input, usually in the form of thermodynamics, to be brought to bear on a range of topical problems, often "state of the art". These present a diverse range of applications for our techniques. The message for the reader is that:

- VBT and TDR can be applied in numerous situations;

- Their application can lead to surprising new results as well as confirmatory ones;

- The basic application is usually very straightforward (Table 6).

\section{Acknowledgements}

LG and HDBJ thank their respective institutions for providing facilities for the execution of this work. Witali Beichel (Freiburg) is thanked for helpful discussion on ILs. The Curtin University Library is thanked for providing the means by which this article is available in Open Access.

\section{References}

1 Chemical Abstracts Service, CAS Content, https://www.cas. org/content/cas-databases, accessed May, 2016.

2 L. Glasser, Crystallographic Information Resources, J. Chem. Educ., 2016, 93, 542-549.

3 E. I. Izgorodina, Towards large-scale, fully $a b$ initio calculations of ionic liquids, Phys. Chem. Chem. Phys., 2011, 13, 4189-4207.

4 G. W. Castellan, Physical Chemistry, Addison-Wesley, Reading, MA, 2nd edn, 1971.

5 B. Wunderlich, Pure Appl. Chem., 1989, 61, 1347-1351.

6 L. Glasser and H. D. B. Jenkins, Ambient Isobaric Heat Capacities, $C_{\mathrm{p}, \mathrm{m}}$, for ionic solids and liquids: an Application of Volume-Based Thermodynamics (VBT), Inorg. Chem., 2011, 50, 8565-8569.

7 M. S. Westwell, M. S. Searle, D. J. Wales and D. H. Williams, J. Am. Chem. Soc., 1995, 117, 5013-5015.

8 C. J. E. Kempster and H. Lipson, Acta Crystallogr., Sect. B: Struct. Crystallogr. Cryst. Chem., 1972, 28, 3674.
9 H. D. B. Jenkins and L. Glasser, Difference rule - A new thermodynamic principle: Prediction of standard thermodynamic data for inorganic solvates, J. Am. Chem. Soc., 2004, 126, 15809-15817.

10 L. Piela, Ideas of quantum chemistry, Elsevier, Amsterdam, 2013.

$11 \mathrm{~W}$. Koch and M. C. Holthausen, A chemist's guide to density functional theory, Wiley-VCH, Weinheim, New York, 2001.

12 L. Glasser and H. D. B. Jenkins, Predictive thermodynamics for condensed phases, Chem. Soc. Rev., 2005, 34, 866-874.

13 L. Glasser and H. D. B. Jenkins, Volume-Based Thermodynamics: A Prescription for Its Application and Usage in Approximation and Prediction of Thermodynamic Data, J. Chem. Eng. Data, 2011, 56, 874-880.

14 H. D. B. Jenkins and L. Glasser, Thermodynamic Difference Rules: A Prescription for their Application and Usage to Approximate Thermodynamic Data, J. Chem. Eng. Data, 2010, 55, 4231-4238.

15 H. D. B. Jenkins, L. Glasser and J. F. Liebman, The Thermodynamic Hydrate Difference Rule (HDR) Applied to Salts of Carbon-Containing Oxyacid Salts and Their Hydrates: Materials at the Inorganic-Organic Interface, J. Chem. Eng. Data, 2010, 55, 4369-4371.

16 L. Glasser and H. D. B. Jenkins, The thermodynamic solvate difference rule: Solvation parameters and their use in interpretation of the role of bound solvent in condensed-phase solvates, Inorg. Chem., 2007, 46, 9768-9778.

17 L. Glasser, Thermodynamic estimation: Ionic materials, J. Solid State Chem., 2013, 206, 139-144.

18 C. H. Yoder and N. J. Flora, Geochemical applications of the simple salt approximation to the lattice energies of complex materials, Am. Mineral., 2005, 90, 488-496.

19 H. D. B. Jenkins, Chemical Thermodynamics - at a glance, Blackwell Publishing, Oxford, 2008.

20 L. Glasser, Correct Use of Helmholtz and Gibbs Function Differences, $\Delta A$ and $\Delta G$ : The van't Hoff Reaction Box, J. Chem. Educ., 2016, 93, 978-980.

21 H. S. Elliott, J. F. Lehmann, H. P. A. Mercier, H. D. B. Jenkins and G. J. Schrobilgen, X-ray Crystal Structures of XeF.MF $\mathbf{M F}_{6}$ $(\mathrm{M}=\mathrm{As}, \mathrm{Sb}, \mathrm{Bi}), \mathrm{XeF} \cdot \mathrm{M}_{2} \mathrm{~F}_{11}(\mathrm{M}=\mathrm{Sb}, \mathrm{Bi})$ and Estimated Thermochemical Data and Predicted Stabilities for Noble-Gas Fluorocation Salts using Volume-Based Thermodynamics, Inorg. Chem., 2010, 49, 8504-8523.

22 L. V. Gurvich, Reference books and data banks on the thermodynamic properties of individual substances, Pure Appl. Chem., 1989, 61, 1027-1031.

23 H. Nyman, T. Talonen, A. Roine, M. Hupa and J. Corander, Statistical Approach to Quality Control of Large Thermodynamic Databases, Metall. Mater. Trans. B, 2012, 43, 1113-1118.

24 H. D. B. Jenkins, L. Glasser, T. M. Klapötke, M. J. Crawford, K. K. Bhasin, J. Lee, G. J. Schrobilgen, L. S. Sunderlin and J. F. Liebman, The ionic isomegethic rule and additivity relationships: Estimation of ion volumes. a route to the energetics and entropics of new, traditional, hypothetical, and counterintuitive ionic materials, Inorg. Chem., 2004, 43, 6238-6248. 
25 N. Cohen and S. W. Benson, Estimation of heats of formation of organic compounds by additivity methods, Chem. Rev., 1993, 93, 2419-2438.

26 P. J. Linstrom and W. G. Mallard, NIST Chemistry WebBook, http://webbook.nist.gov/chemistry/, accessed April, 2016.

27 A. F. Kapustinskii, Lattice energy of ionic crystals, Q. Rev., Chem. Soc., 1956, 10, 283-294.

28 T. E. Mallouk, G. L. Rosenthal, R. Muller, R. Brusasco and N. Bartlett, Fluoride ion affinities of germanium tetrafluoride and boron trifluoride from thermodynamic and structural data for $\left(\mathrm{SF}_{3}\right)_{2} \mathrm{GeF}_{6}, \mathrm{ClO}_{2} \mathrm{GeF}_{5}$, and $\mathrm{ClO}_{2} \mathrm{BF}_{4}$, Inorg. Chem., 1984, 23, 3167-3173.

29 T. E. Mallouk, PhD thesis, University of Berkeley, CA, 1983.

30 C. Shen, R. Hagiwara, T. E. Mallouk and N. Bartlett, in ACS Symp. Ser. No. 555, ed. J. Thrasher and S. Strauss, ACS, Washington, DC, 1994, pp. 26-39.

31 D. Gibler, PhD thesis, Princeton University, NJ, 1974.

32 H. D. B. Jenkins, H. K. Roobottom, J. Passmore and L. Glasser, Relationships among ionic lattice energies, molecular (formula unit) volumes, and thermochemical radii, Inorg. Chem., 1999, 38, 3609-3620.

33 L. Glasser, Lattice Energies of Crystals with Multiple Ions - a Generalised Kapustinskii Equation, Inorg. Chem., 1995, 34, 4935-4936.

34 H. D. B. Jenkins and L. Glasser, Volume-based thermodynamics: Estimations for 2:2 salts, Inorg. Chem., 2006, 45, 1754-1756.

35 L. Glasser and H. D. B. Jenkins, Lattice energies and unit cell volumes of complex ionic solids, J. Am. Chem. Soc., 2000, 122, 632-638.

36 H. D. B. Jenkins, Thermodynamics of the Relationship between Lattice Energy and Lattice Enthalpy, J. Chem. Educ., 2005, 82, 950-952.

37 P. Vieillard, Thermodynamics of Hydration in Minerals: How to Predict These Entities, in Thermodynamics - Fundamentals and Its Application in Science, ed. R. Morales-Rodriguez, InTech, 2012.

38 L. Glasser, Lattice and phase transition thermodynamics of ionic liquids, Thermochim. Acta, 2004, 421, 87-93.

39 H. D. B. Jenkins, Ionic liquids - an overview, Sci. Prog., 2011, 94, 265-297.

40 H. D. B. Jenkins, Recent initiatives in experimental thermodynamic studies on ionic liquids [IL] - the emergence of a standard thermochemical database for ILs, Sci. Prog., 2011, 94, 184-210.

41 C. Robelin, Models for the thermodynamic properties of molten salt systems: Perspectives for ionic liquids, Fluid Phase Equilib., 2016, 409, 482-494.

42 J. P. Hallett and T. Welton, Room-Temperature Ionic Liquids: Solvents for Synthesis and Catalysis. 2, Chem. Rev., 2011, 111, 3508-3576.

43 H. Niedermeyer, J. P. Hallett, I. J. Villar-Garcia, P. A. Hunt and T. Welton, Mixtures of ionic liquids, Chem. Soc. Rev., 2012, 41, 7780-7802.

44 S. Keskin, D. Kayrak-Talay, U. Akman and Ö. Hortaçsu, A review of ionic liquids towards supercritical fluid applications, J. Supercrit. Fluids, 2007, 43, 150-180.
45 A. R. Katritzky, R. Jain, A. Lomaka, R. Petrukhin, M. Karelson, A. E. Visser and R. D. Rogers, Correlation of the Melting Points of Potential Ionic Liquids (Imidazolium Bromides and Benzimidazolium Bromides) Using the CODESSA Program [J. Chem. Inf. Comput. Sci., 2002, 42, 225-231], J. Chem. Inf. Model., 2005, 45, 533-534.

46 A. R. Katritzky, A. Lomaka, R. Petrukhin, R. Jain, M. Karelson, A. E. Visser and R. D. Rogers, QSPR Correlation of the Melting Point for Pyridinium Bromides, Potential Ionic Liquids, J. Chem. Inf. Comput. Sci., 2002, 42, 71-74.

47 M. Deetlefs, K. R. Seddon and M. Shara, Predicting physical properties of ionic liquids, Phys. Chem. Chem. Phys., 2006, 8, 642-649.

48 D. Wileńska, I. Anusiewicz, S. Freza, M. Bobrowski, E. Laux, S. Uhl, H. Keppner and P. Skurski, Predicting the viscosity and electrical conductivity of ionic liquids on the basis of theoretically calculated ionic volumes, Mol. Phys., 2015, 113, 630-639.

49 J. M. Slattery, C. Daguenet, P. J. Dyson, T. J. S. Schubert and I. Krossing, How to predict the physical properties of ionic liquids: A volume-based approach, Angew. Chem., Int. Ed., 2007, 46, 5384-5388.

50 K. E. Gutowski, J. D. Holbrey, R. D. Rogers and D. A. Dixon, Prediction of the formation and stabilities of energetic salts and ionic liquids based on $a b$ initio electronic structure calculations, J. Phys. Chem. B, 2005, 109, 23196-23208.

51 K. E. Gutowski, R. D. Rogers and D. A. Dixon, Accurate thermochemical properties for energetic materials applications. I. Heats of formation of nitrogen-containing heterocycles and energetic precursor molecules from electronic structure theory, J. Phys. Chem. A, 2006, 110, 11890-11897.

52 K. E. Gutowski, R. D. Rogers and D. A. Dixon, Accurate thermochemical properties for energetic materials applications. II. Heats of formation of imidazolium-, 1,2,4-triazolium-, and tetrazolium-based energetic salts from isodesmic and lattice energy calculations, J. Phys. Chem. B, 2007, 111, 4788-4800.

53 H. D. B. Jenkins and L. Glasser, Standard absolute entropy, $S_{298}^{\circ}$, values from volume or density. 1. Inorganic materials, Inorg. Chem., 2003, 42, 8702-8708.

54 I. Krossing, J. M. Slattery, C. Daguenet, P. J. Dyson, A. Oleinikova and $\mathrm{H}$. Weingartner, Why are ionic liquids liquid? A simple explanation based on lattice and solvation energies, J. Am. Chem. Soc., 2006, 128, 13427-13434.

55 U. Preiss, S. Bulut and I. Krossing, In Silico Prediction of the Melting Points of Ionic Liquids from Thermodynamic Considerations: A Case Study on 67 Salts with a Melting Point Range of $337^{\circ} \mathrm{C}$, J. Phys. Chem. B, 2010, 114, 11133-11140.

56 U. P. Preiss, W. Beichel, A. M. T. Erle, Y. U. Paulechka and I. Krossing, Is Universal, Simple Melting Point Prediction Possible?, ChemPhysChem, 2011, 12, 2959-2972.

57 U. Preiss, J. M. Slattery and I. Krossing, In Silico Prediction of Molecular Volumes, Heat Capacities, and TemperatureDependent Densities of Ionic Liquids, Ind. Eng. Chem. Res., 2009, 48, 2290-2296.

58 U. Preiss, C. Jungnickel, J. Thoming, I. Krossing, J. Luczak, M. Diedenhofen and A. Klamt, Predicting the Critical Micelle 
Concentrations of Aqueous Solutions of Ionic Liquids and Other Ionic Surfactants, Chem. - Eur. J., 2009, 15, 8880-8885.

59 W. Beichel, U. P. Preiss, S. P. Verevkin, T. Koslowski and I. Krossing, Empirical description and prediction of ionic liquids' properties with augmented volume-based thermodynamics, J. Mol. Liq., 2014, 192, 3-8.

60 L. Glasser and H. A. Scheraga, Calculations on Crystal Packing of a Flexible Molecule: Leu-Enkephalin, J. Mol. Biol., 1988, 199, 513-524.

61 J. D. Gale, GULP: A computer program for the symmetryadapted simulation of solids, J. Chem. Soc., Faraday Trans., 1997, 93, 629-637.

62 E. I. Izgorodina, U. L. Bernard, P. M. Dean, J. M. Pringle and D. R. MacFarlane, The Madelung Constant of Organic Salts, Cryst. Growth Des., 2009, 9, 4834-4839.

63 L. Glasser, Solid-State Energetics and Electrostatics: Madelung Constants and Madelung Energies, Inorg. Chem., 2012, 51, 2420-2424.

64 H. D. B. Jenkins and J. F. Liebman, Volumes of solid state ions and their estimation, Inorg. Chem., 2005, 44, 6359-6372.

65 Y. Marcus, Ion Properties, Marcel Dekker, New York, 1997.

66 Y. Marcus, Ions in Solution and their Solvation, Wiley, 2015. 67 W. M. Latimer, Methods of Estimating the Entropies of Solid Compounds, J. Am. Chem. Soc., 1951, 73, 1480-1482.

68 P. J. Spencer, Estimation of thermodynamic data for metallurgical applications, Thermochim. Acta, 1998, 314, 1-21.

69 Outotec, HSC Chemistry 8, http://www.outotec.com/en/Pro ducts--services/HSC-Chemistry/, accessed April, 2016.

70 National Institute for Materials Science, AtomWork Inorganic Material Database, http://crystdb.nims.go.jp/index_en.html, accessed June, 2016.

71 in CRC Handbook of Chemistry and Physics, ed. W. M. Haynes, CRC Press, Boca Raton, 2015.

72 L. Glasser, Simple Route to Lattice Energies in the Presence of Complex Ions, Inorg. Chem., 2012, 51, 10306-10310.

73 T. S. Cameron, R. J. Deeth, I. Dionne, H. B. Du, H. D. B. Jenkins, I. Krossing, J. Passmore and H. K. Roobottom, Bonding, structure, and energetics of gaseous $\mathrm{E}_{8}{ }^{2+}$ and of solid $\mathrm{E}_{8}\left(\mathrm{AsF}_{6}\right)_{2}$ ( $\mathrm{E}=\mathrm{S}, \mathrm{Se})$, Inorg. Chem., 2000, 39(25), 5614-5631.

74 S. Brownridge, I. Krossing, J. Passmore, H. D. B. Jenkins and H. K. Roobottom, Recent advances in the understanding of the syntheses, structures, bonding and energetics of the homopolyatomic cations of Groups 16 an 17, Coord. Chem. Rev., 2000, 197, 397-481.

75 H. D. B. Jenkins, H. K. Roobottom and J. Passmore, Estimation of enthalpy data for reactions involving gas phase ions utilizing lattice potential energies: Fluoride ion affinities (FIA) and $\mathrm{pF}(-)$ values of $m \mathrm{SbF}_{5}(\mathrm{I})$ and $m \mathrm{SbF}_{5}(\mathrm{~g})(m=1,2,3)$, $\mathrm{AsF}_{5}(\mathrm{~g}), \mathrm{AsF}_{5} \cdot \mathrm{SO}_{2}(\mathrm{c})$. Standard enthalpies of formation: $\Delta \mathrm{H}_{\mathrm{f}}{ }^{\circ}\left(\mathrm{Sb}_{m} \mathrm{~F}_{5 m+1}{ }^{-}, \mathrm{g}\right)(m=1,2,3), \Delta \mathrm{H}_{\mathrm{f}}{ }^{\circ}\left(\mathrm{AsF}_{6}{ }^{-}, \mathrm{g}\right)$, and $\Delta \mathrm{H}_{\mathrm{f}}{ }^{\circ}\left(\mathrm{NF}_{4}{ }^{+}, \mathrm{g}\right)$, Inorg. Chem., 2003, 42(9), 2886-2893.

76 H. D. B. Jenkins, I. Krossing, J. Passmore and I. Raabe, A computational study of $\mathrm{Sb}_{n} \mathrm{~F}_{5 n}(n=1-4)$ - Implications for the fluoride ion affinity of $\mathrm{nSbF}_{5}, J$. Fluorine Chem., 2004, 125(11), 1585-1592.
77 T. S. Cameron, I. Dionne, H. D. B. Jenkins, S. Parsons, J. Passmore and H. K. Roobottom, Preparation, X-ray Crystal Structure Determination, Lattice Potential Energy, and Energetics of Formation of the Salt $\mathrm{S}_{4}\left(\mathrm{AsF}_{6}\right)_{2} \cdot \mathrm{AsF}_{3}$ Containing the Lattice-Stabilized Tetrasulfur $[2+]$ Cation. Implications for the Understanding of the Stability of $\mathrm{M}_{4}{ }^{2+}$ and $\mathrm{M}^{2+}$ $(\mathrm{M}=\mathrm{S}$, Se, and Te) Crystalline Salts, Inorg. Chem., 2000, 39(10), 2042-2052.

78 K. O. Christe and H. D. B. Jenkins, Quantitative measure for the "nakedness" of fluoride ion sources, J. Am. Chem. Soc., 2003, 125(31), 9457-9461.

79 K. O. Christe and H. D. B. Jenkins, Quantitative measure for the "nakedness" of fluoride ion sources, J. Am. Chem. Soc., 2003, 125, 14210.

80 H. D. B. Jenkins and D. Tudela, New methods to estimate lattice energies - Application to the relative stabilities of bisulfite ( $\left.\mathrm{HSO}_{3}{ }^{-}\right)$and metabisulfite $\left(\mathrm{S}_{2} \mathrm{O}_{5}{ }^{2-}\right)$ salts, J. Chem. Educ., 2003, 80(12), 1482-1487.

81 A. Decken, H. D. B. Jenkins, G. B. Nikiforov and J. Passmore, The reaction of $\mathrm{LiAl}(\mathrm{OR})_{4} \mathrm{R}=\mathrm{OC}\left(\mathrm{CF}_{3}\right)_{2} \mathrm{Ph}, \mathrm{OC}\left(\mathrm{CF}_{3}\right)_{3}$ with $\mathrm{NO} / \mathrm{NO}_{2}$ giving $\mathrm{NO} \cdot \mathrm{Al}(\mathrm{OR})_{4}, \mathrm{LiNO}_{3}$ and $\mathrm{N}_{2} \mathrm{O}$. The synthesis of $\mathrm{NO} \cdot \mathrm{Al}(\mathrm{OR})_{4}$ from $\mathrm{LiAl}(\mathrm{OR})$ and $\mathrm{NO}^{-\mathrm{SbF}_{6}}$ in sulfur dioxide solution, Dalton Trans., 2004, (16), 2496-2504.

82 D. A. Dixon, D. Feller, K. O. Christe, W. W. Wilson, A. Vij, V. Vij, H. D. B. Jenkins, R. M. Olson and M. S. Gordon, Enthalpies of Formation of Gas-Phase $\mathrm{N}_{3}, \mathrm{~N}_{3}{ }^{-}, \mathrm{N}_{5}{ }^{+}$, and $\mathrm{N}_{5}{ }^{-}$from $A b$ Initio Molecular Orbital Theory, Stability Predictions for $\mathrm{N}_{5}{ }^{+} \mathrm{N}_{3}{ }^{-}$and $\mathrm{N}_{5}{ }^{+} \mathrm{N}_{5}{ }^{-}$, and Experimental Evidence for the Instability of $\mathrm{N}_{5}{ }^{+} \mathrm{N}_{3}{ }^{-}$, J. Am. Chem. Soc., 2004, 126(3), 834-843.

83 K. O. Christe, A. Vij, W. W. Wilson, V. Vij, D. A. Dixon, D. Feller and H. D. B. Jenkins, $\mathrm{N}_{5}{ }^{+} \mathrm{N}_{5}{ }^{-}$allotrope is California dreaming, Chem. Br., 2003, 39(9), 17.

84 D. R. Rosseinsky, L. Glasser and H. D. B. Jenkins, Thermodynamic clarification of the curious ferric/potassium ion exchange accompanying the electrochromic redox reactions of Prussian blue, iron(III) hexacyanoferrate(II), J. Am. Chem. Soc., 2004, 126(33), 10472-10477.

85 A. Decken, H. D. B. Jenkins, C. Knapp, G. B. Nikiforov, J. Passmore and J. M. Rautiainen, The autoionization of [ $\left.\mathrm{TiF}_{4}\right]$ by cation complexation with $[15]$ crown-5 to give $\left[\mathrm{TiF}_{2}([15]-\right.$ crown-5)][ $\left.\mathrm{Ti}_{4} \mathrm{~F}_{18}\right]$ containing the tetrahedral $\left[\mathrm{Ti}_{4} \mathrm{~F}_{18}\right]^{2-}$ ion, Angew. Chem., Int. Ed., 2005, 44, 7958-7961.

86 K. K. Bhasin, M. J. Crawford, H. D. B. Jenkins and T. M. Klapötke, The volume-based thermodynamics (VBT) and attempted preparation of an isomeric salt, nitryl chlorate: $\mathrm{NO}_{2} \cdot \mathrm{ClO}_{3}, Z$. Anorg. Allg. Chem., 2006, 632(5), 897-900.

87 S. Brownridge, L. Calhoun, H. D. B. Jenkins, R. S. Laitinen, M. P. Murchie, J. Passmore, J. Pietikainen, J. M. Rautiainen, J. C. P. Sanders, G. J. Schrobilgen, R. J. Suontamo, H. M. Tuononen, J. U. Valkonen and C. M. Wong, ${ }^{77} \mathrm{Se}$ NMR Spectroscopic, DFT MO, and VBT Investigations of the Reversible Dissociation of Solid $\left(\mathrm{Se}_{6} \mathrm{I}_{2}\right)\left[\mathrm{AsF}_{6}\right]_{2} \cdot 2 \mathrm{SO}_{2}$ in Liquid $\mathrm{SO}_{2}$ to Solutions Containing $1,4-\mathrm{Se}_{6} \mathrm{I}_{2}{ }^{2+}$ in Equilibrium with $\mathrm{Se}_{\mathrm{n}}{ }^{2+}(n=4,8,10)$ and Seven Binary Selenium Iodine Cations: Preliminary Evidence for $1,1,4,4-\mathrm{Se}_{4} \mathrm{Br}_{4}{ }^{2+}$ and cyclo-Se ${ }_{7} \mathrm{Br}^{+}$, Inorg. Chem., 2009, 48(5), 1938-1959. 
88 H. S. Elliott, J. F. Lehmann, H. P. A. Mercier, H. D. B. Jenkins and G. J. Schrobilgen, X-ray Crystal Structures of XeF.MF $(\mathrm{M}=\mathrm{As}, \mathrm{Sb}, \mathrm{Bi}), \mathrm{XeF} \cdot \mathrm{M}_{2} \mathrm{~F}_{11}(\mathrm{M}=\mathrm{Sb}, \mathrm{Bi})$ and Estimated Thermochemical Data and Predicted Stabilities for NobleGas Fluorocation Salts using Volume-Based Thermodynamics, Inorg. Chem., 2010, 49(18), 8504-8523.

89 H. D. B. Jenkins, L. Glasser and J. F. Liebman, The Thermodynamic Hydrate Difference Rule (HDR) Applied to Salts of Carbon-Containing Oxyacid Salts and Their Hydrates: Materials at the Inorganic-Organic Interface, J. Chem. Eng. Data, 2010, 55(10), 4369-4371.

90 L. Glasser and F. Jones, Systematic Thermodynamics of Hydration (and of Solvation) of Inorganic Solids, Inorg. Chem., 2009, 48(4), 1661-1665.

91 K. O. Christe, R. Haiges, J. A. Boatz, H. D. B. Jenkins, E. B. Garner and D. A. Dixon, Why Are $\left[\mathrm{P}\left(\mathrm{C}_{6} \mathrm{H}_{5}\right)_{4}\right]^{+} \mathrm{N}_{3}{ }^{-}$and $\left[\mathrm{As}\left(\mathrm{C}_{6} \mathrm{H}_{5}\right)_{4}\right]^{+} \mathrm{N}_{3}^{-}$Ionic Salts and $\mathrm{Sb}\left(\mathrm{C}_{6} \mathrm{H}_{5}\right)_{4} \mathrm{~N}_{3}$ and $\mathrm{Bi}\left(\mathrm{C}_{6} \mathrm{H}_{5}\right)_{4} \mathrm{~N}_{3}$ Covalent Solids? A Theoretical Study Provides an Unexpected Answer, Inorg. Chem., 2011, 50, 3752-3756.

92 A. Vegas, J. F. Liebman and H. D. B. Jenkins, Unique thermodynamic relationships for $\Delta_{\mathrm{f}} H^{\circ}$ and $\Delta_{\mathrm{f}} G^{\circ}$ for crystalline inorganic salts. I. Predicting the possible existence and synthesis of $\mathrm{Na}_{2} \mathrm{SO}_{2}$ and $\mathrm{Na}_{2} \mathrm{SeO}_{2}$, Acta Crystallogr., Sect. B: Struct. Sci., 2012, 68, 511-527.

93 D. Srinivas, V. Ghule, K. Muralidharan and H. D. B. Jenkins, Tetraanionic Nitrogen-Rich Tetrazole-Based salts, Chem. Asian J., 2013, 8, 1023-1028.

94 P. Bruna, A. Decken, S. Greer, F. Grein, H. D. B. Jenkins, B. Mueller, J. Passmore, T. A. P. Paulose, J. M. Rautiainen and S. Richardson, Synthesis of (TDAE) $\left(\mathrm{O}_{2} \mathrm{SSSSO}_{2}\right)$ and Discovery of (TDAE) $\left(\mathrm{O}_{2} \mathrm{SSSSO}_{2}\right)(\mathrm{s})$ containing the first polythionite anion, Inorg. Chem., 2013, 52, 13651-13662.

95 L. Glasser, H. D. B. Jenkins and T. M. Klapötke, Is the VBT Approach valid for estimation of the lattice enthalpy of salts containing the 5,5'-(Tetrazole- $1 N$-oxide) ${ }^{2-}$ ?, Z. Anorg. Allg. Chem., 2014, 640, 1297-1299.

96 H. D. B. Jenkins, D. Holland and A. Vegas, Thermodynamic data for crystalline arsenic and phosphorus compounds, $\mathrm{M}_{2} \mathrm{O}_{5} \cdot n \mathrm{H}_{2} \mathrm{O}$ reexamined using the Thermodynamic Difference Rules, Thermochim. Acta, 2016, 633, 24-30.

97 H. D. B. Jenkins, D. Holland and A. Vegas, An assessment of the TDR for mixed inorganic oxides and comments on the enthalpies of formation of phosphates, Thermochim. Acta, 2015, 601, 63-67. 